MRS Advances (C) 2020 Materials Research Society. This is an Open Access article, distributed under the terms of the Creative Commons Attribution-NonCommercialShareAlike licence (http://creativecommons.org/licenses/by-ncsa/4.0/), which permits non-commercial re-use, distribution, and reproduction in any medium, provided the same Creative Commons licence is included and the original work is properly cited. The written permission of Cambridge University Press must be obtained for commercial re-use.

DOI: $10.1557 / \operatorname{adv} .2020 .90$

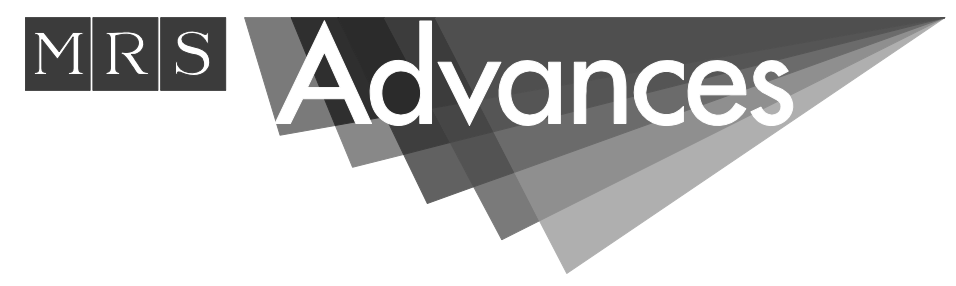

\title{
Improved cyclability of Nickel-rich layered oxides
}

Nils P. Wagner ${ }^{1,2^{*}}$, Julian R. Tolchard ${ }^{1}$, Artur Tron ${ }^{1}$, Harald N. Pollen ${ }^{2}$, Heiko Gaertner ${ }^{1}$, Per E. Vullum ${ }^{3,4}$

${ }^{1}$ Department of Sustainable Energy Technology, SINTEF Industry, 7491 Trondheim, Norway

${ }^{2}$ Department of Materials Science and Engineering, Norwegian University of Science and Technology, 7491 Trondheim, Norway

${ }^{3}$ Department of Materials and Nanotechnology, SINTEF Industry, 7491 Trondheim, Norway

${ }^{4}$ Department of Physics, Norwegian University of Science and Technology, 7491 Trondheim, Norway

*Corresponding author: Nils Peter Wagner nils.peter.wagner@sintef.no

ABSTRACT

This study compares the physico- and electro- chemical properties of $\mathrm{LiNi}_{0.8} \mathrm{Mn}_{0.10} \mathrm{Co}_{0.1} \mathrm{O}_{2}(\mathrm{NMC} 811)$ and $\mathrm{LiNi}_{0.83} \mathrm{Mn}_{0.06} \mathrm{Co}_{0.09} \mathrm{Al}_{0.1} \mathrm{O}_{2}$ (NMCA) prepared by an oxalic acid co-precipitation. Deposition of a $\mathrm{SiO}_{2}$ surface coating was attempted via reaction of the powder with an amino silane prior to the final heat treatment. It was found that either the presence of small amounts of $\mathrm{Al}^{3+}$, or the compositional gradient resulting from a two step co-precipitation, caused increased crystal growth of the NMCA in comparison to NMC811. This led to improved cyclability in LP40 electrolyte. However, the $\mathrm{SiO}_{2}$ coating appeared incomplete and negatively impacted performance. Crystal cleavage preferably on the $\{001\}$ planes was observed after 100 charge-discharge cycles, 
with consequent cathode electrolyte interphase formation in the crystal cracks. This is believed to cause capacity decay via lithium loss, and increased charge transfer resistance. An FEC based electrolyte improved the cyclability in all cases and even under extreme conditions $\left(45^{\circ} \mathrm{C}\right.$ and upper cycling potential of $\left.4.5 \mathrm{~V}\right)$ NMCA showed a capacity retention of $85 \%$ after 100 cycles.

\section{INTRODUCTION:}

Ni-rich layered lithium oxides $\left(\mathrm{LiNi}_{1-\mathrm{x}} \mathrm{M}_{\mathrm{x}} \mathrm{O}_{2} ; 0<\mathrm{x}<0.4\right.$; where $\mathrm{M}$ is most often $\mathrm{Mn}, \mathrm{Co}, \mathrm{Al}$ or a combination of these) are state of the art cathode materials for Li-ion batteries.[1,2] Raising the Ni content to values $>80 \%$ will further increase the specific capacity, and layered oxides with $\mathrm{Ni}$ contents of over $80 \mathrm{wt} . \%$ are the most promising cathode materials for next-generation LIBs.[3,4] However, lowering $\mathrm{Co}$ and $\mathrm{Mn}$ concentrations in the structure impacts the thermal stability and capacity retention.[2] In a highly charged state, the delithiated Ni-rich layered oxide is prone to oxygen loss, leading to transformation to spinel and rock salt structures close to the surface.[5,6] Electrolyte decomposition, and the formation of a high resistivity cathode interphase (CEI), further impede the kinetics and cause capacity decay.[7,8] Related to this issue it is well known that secondary Ni-rich layered oxide particles tend to crack along the grain boundaries upon cycling. This cracking is caused by an anisotropic contraction in the unit cell c-direction through the $\mathrm{H} 2-\mathrm{H} 3$ phase transition at high levels of delithiation. $[9,10]$ Fractures along the grain boundaries of the secondary particles then allow for electrolyte penetration and further CEI formation on the newly generated surfaces.[11] Dahn and co-workers recently reported $\mathrm{Mg}$ and $\mathrm{Al}$ to be most promising in suppressing the phase transitions at high states of charge and reducing reactivity towards the electrolyte.[12] The authors further stressed the importance of surface coatings. Increased cyclability of Ni-rich layered oxides via use of a thin protective coating (with e.g. $\left.\mathrm{Al}_{2} \mathrm{O}_{3}\right)$ is often reported.[13,14] Other strategies include functional electrolyte additives, alternative solvents with higher oxidative stability, and core-shell or concentration gradient structures.[12,15,16,17] Lately, micron sized single crystalline layered oxides have gained attention as they can alleviate excessive surface exposure from grain boundary cracking.[18] Here we report a simple one-pot oxalic acid coprecipitation of $\mathrm{LiNi}_{0.8} \mathrm{Mn}_{0.10} \mathrm{Co}_{0.1} \mathrm{O}_{2}$ (NMC811) and $\mathrm{LiNi}_{0.83} \mathrm{Mn}_{0.06} \mathrm{Co}_{0.09} \mathrm{Al}_{0.1} \mathrm{O}_{2}$ (NMCA), and the influence of concentration gradients in the precipitate on the sinterability and electrochemical performance. We furthermore elaborate the possibility of coating the optimized material with $\mathrm{SiO}_{2}$ by grafting an amino-silane on the particle surface prior to the annealing step.

\section{EXPERIMENTAL:}

\section{Materials synthesis and physiochemical characterization}

NMC811 $\left(\mathrm{LiNi}_{0.8} \mathrm{Mn}_{0.10} \mathrm{Co}_{0.1} \mathrm{O}_{2}\right)$ and NMCA with the approximate composition $\mathrm{LiNi}_{0.83} \mathrm{Mn}_{0.06} \mathrm{Co}_{0.09} \mathrm{Al}_{0.1} \mathrm{O}_{2}$ were synthesized by an oxalate co-precipitation. All chemicals were purchased at Sigma-Aldrich and Alfa Aesar in reagent grade with $\geq 98 \%$ purity. Three metal cation solutions were used, of compositions as listed in Table 1. 


\begin{tabular}{|c|c|c|c|}
\hline \multirow{3}{*}{ Component } & \multicolumn{3}{|c|}{ Composition } \\
\hline & $\underline{\text { NMC811 }}$ & $\underline{\text { NMCA }}$ & \\
\hline & & Soln 1 & Soln 2 \\
\hline $\mathrm{Ni}\left(\mathrm{CH}_{3} \mathrm{COO}\right)_{2} \quad 4 \mathrm{H}_{2} \mathrm{O}$ & $48 \mathrm{mmol}$ & $50.4 \mathrm{mmol}$ & $12 \mathrm{mmol}$ \\
\hline $\mathrm{Mn}\left(\mathrm{CH}_{3} \mathrm{COO}\right)_{2} \quad 4 \mathrm{H}_{2} \mathrm{O}$ & $6 \mathrm{mmol}$ & $4.8 \mathrm{mmol}$ & - \\
\hline $\mathrm{Co}\left(\mathrm{CH}_{3} \mathrm{COO}\right)_{2} \quad 4 \mathrm{H}_{2} \mathrm{O}$ & $6 \mathrm{mmol}$ & $4.8 \mathrm{mmol}$ & $2.25 \mathrm{mmol}$ \\
\hline $\mathrm{LiNO}_{3}$ & $64.5 \mathrm{mmol}$ & $64.5 \mathrm{mmol}$ & $16.13 \mathrm{mmol}$ \\
\hline $\mathrm{Al}\left(\mathrm{NO}_{3}\right)_{3} \quad 9 \mathrm{H}_{2} \mathrm{O}$ & - & - & $0.75 \mathrm{mmol}$ \\
\hline $\mathrm{H}_{2} \mathrm{O}$ & $200 \mathrm{ml}$ & $200 \mathrm{ml}$ & $50 \mathrm{ml}$ \\
\hline $\mathrm{CH}_{3} \mathrm{CH}_{2} \mathrm{OH}$ & $200 \mathrm{ml}$ & $200 \mathrm{ml}$ & $50 \mathrm{ml}$ \\
\hline $\mathrm{CH}_{3} \mathrm{COOH}$ & $25 \mathrm{ml}$ & $25 \mathrm{ml}$ & $10 \mathrm{ml}$ \\
\hline
\end{tabular}

To synthesize NMC811, the solution described in Table 1 was dripped over a period of $4 \mathrm{hrs}$ into a solution comprising $240 \mathrm{mmol}$ oxalic acid dissolved in $400 \mathrm{ml}$ of a 1:1 mixture of $\mathrm{H}_{2} \mathrm{O}: \mathrm{EtOH}$, under constant stirring and at a temperature of $60{ }^{\circ} \mathrm{C}$. To synthesize NMCA, solutions 1 and 2 as described in Table 1 were dripped successively into a similar oxalic acid solution under the same reaction conditions. After precipitation, the suspensions were aged $20 \mathrm{~h}$ under stirring before solvent evaporation. The resulting powders were ground and calcined at $450^{\circ} \mathrm{C}$ for $5 \mathrm{~h}$. After calcination the powders were reground and fired at $800^{\circ} \mathrm{C}$ for $20 \mathrm{~h}$ under flowing $\mathrm{O}_{2}(5 \mathrm{Nl} / \mathrm{h})$. The as-fired $\mathrm{NMC} 811$ and NMCA products were ground and sieved to $40 \mu \mathrm{m}$. $\mathrm{SiO}_{2}$-decorated NMCA was prepared by treating the calcined NMCA powder with $2 \mathrm{wt} \%$ (3-Aminopropyl)triethoxysilane (APTES) at $80^{\circ} \mathrm{C}$ in $\mathrm{EtOH}$ for $20 \mathrm{~h}$. The silane treated powder was dried and annealed as described above. Phase purity and morphology of the samples was analyzed by powder X-ray diffraction using a Bruker D8 Advance A25 diffractometer, with data fitted using the Bruker Topas v5 software. Scanning electron microscopy (SEM) was carried out with a FEI APREO scanning electron microscope, equipped with an Oxford Instruments Aztec energy dispersive x-ray spectroscopy (EDS) system.

\section{$\underline{\text { Electrochemical and post-mortem characterization }}$}

Electrochemical characterization was performed in 2016 coin cells against Li counter electrodes. The working electrodes comprised 85 wt.\% active material, 10 wt.\% Super C65 carbon and 5 wt.\% PVDF. Two different electrolytes, namely $1 \mathrm{M} \mathrm{LiPF}_{6}$ in EC/DEC (1:1 by volume (LP40)) (Aldrich Battery grade) and/or 1.2 $\mathrm{M} \mathrm{LiPF}_{6}$ in FEC/DEC (3:7 by volume), were investigated. Charge-discharge experiments were performed using a LANHE CT $2001 \mathrm{~A}$ battery tester at $20^{\circ} \mathrm{C}$ and $45^{\circ} \mathrm{C}$ and in potential windows of $3.0 \mathrm{~V}$ to $4.3 \mathrm{~V}$ or $3.0 \mathrm{~V}$ to $4.5 \mathrm{~V}$. $1 \mathrm{C}$ was defined as $180 \mathrm{mAhg}^{-1}$. Post-mortem analysis of the NMCA electrode after 100 cycles was performed by SEM and (S)TEM. (S)TEM analysis was performed using a Jeol JEM ARM200F double Cs corrected TEM with a Gatan Quantum ER (EELS) system and a large solid angle (98 srad) Centurio EDS detector. Focused ion beam (FIB) cross sections were generated on a FEI Helios NanoLab DualBeam FIB. 


\section{RESULTS AND DISCUSSION:}

Both the synthesized NMC811 and the NMCA were phase pure. The refined powder x-ray patterns of both samples are shown in figures 1(a) and 1(b) respectively. The structure was fitted to the layered $\alpha-\mathrm{NaFeO}_{2}$ structure in the rhombohedral space group R-3m. Lattice parameters for NMC811 were calculated to be $a=b=2.8701$ (1) $\AA$ and $\mathrm{c}=14.1991(5) \AA$ whilst NMCA lattice parameters of $\mathrm{a}=\mathrm{b}=2.8694(1) \AA$ and $\mathrm{c}=$ $14.2000(3) \AA$ were determined. Rietveld refinement indicated $\sim 1.8 \% \mathrm{Li} / \mathrm{Ni}$ site reversal for NMC811 and no quantifiable site reversal for NMCA. A low level of microstrainrelated peak broadening was observed for both samples $\left(\varepsilon_{0}=0.0006\right)$.
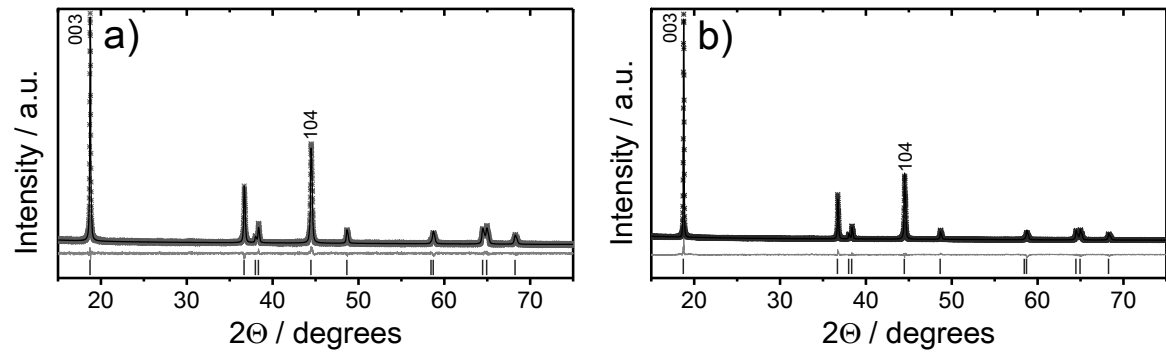

Figure 1: Powder XRD results. a) Full pattern refinement of NMC 811. b) Full pattern refinement of NMCA

The precipitated metal oxalates consisted in both cases of agglomerated nanoneedles, as seen in figure 2(a) and the inset. Heat treatment yielded NMC811 particles consisting of spheroidal agglomerates with grains in the sub- $\mu \mathrm{m}$ range (figure 2(b)). The NMCA sample however showed greater grain growth on firing, with most particles comprising few-crystallite particles or even single crystals in the range of $0.5-2 \mu \mathrm{m}$ (figure 2(c)). It is not known if this increased particle growth is caused by the presence of $1 \mathrm{~atm} . \% \mathrm{Al}$ or the concentration gradient in the precipitate. SEM/EDS of the APTEStreated NMCA sample (figure 2(d)) confirmed the presence of an extremely low concentration of $\sim 0.4$ atm $\%$ silicon. Background measurements were performed to confirm this value was not an instrument artefact. Given the absence of tetrahedral positions in the $\mathrm{LiMO}_{2}$ layered structure, the $\mathrm{Si}$ is expected to be immiscible and thus located at the particle surface. Assuming this, a concentration of $0.4 \mathrm{~atm} \%$ corresponds to less than a surface monolayer and indicates incomplete coverage of the particle surface. 


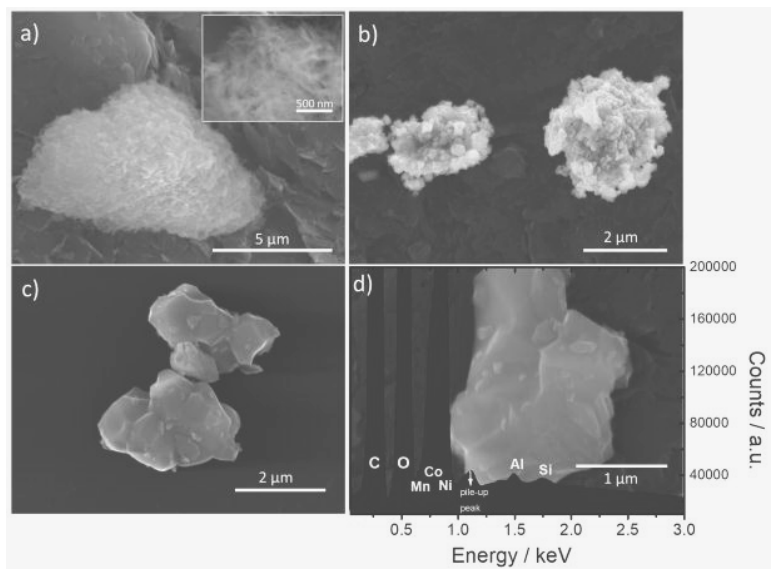

Figure 2. a) SEM micrograph of the co-precipitation product, b) SEM micrograph of annealed NMC 811, c) SEM micrograph of annealed NMCA, d) average EDX spectrum of 100 spectra showing silicon content of the $\mathrm{SiO} 2$ surface treated NMCA sample (average Si content $=0.4$ atm. \%).

Electrodes were produced from all three samples and analyzed in half cell configuration in a potential window of $3.0-4.3 \mathrm{~V}$ vs. $\mathrm{Li} / \mathrm{Li}^{+}$. The voltage profile of the initial two cycles at $\mathrm{C} / 10$, the capacity retention for 100 cycles at $\mathrm{C} / 2$, the rate acceptance and the coulombic efficiency are shown in figures 3 (a-d) respectively. For discharge rates higher than $\mathrm{C} / 2$ the rate on charge was set to $0.8 \mathrm{C}$, with a $\mathrm{CV}$ step at cut-off until the current dropped to $5 \%$ of the initial value. The first cycle efficiency was in all three cases around 86-87\%. NMC811 reached a discharge capacity of $207 \mathrm{mAhg}^{-1}$, NMCA of $195 \mathrm{mAhg}^{-1}$ and the $\mathrm{SiO}_{2}$ treated NMCA showed $186 \mathrm{mAhg}^{-1}$. The second discharge profile reassembled the first. The observation that the NMCA sample reached a lower capacity, despite the higher $\mathrm{Ni}$ content, may be a result of the particle size differences.
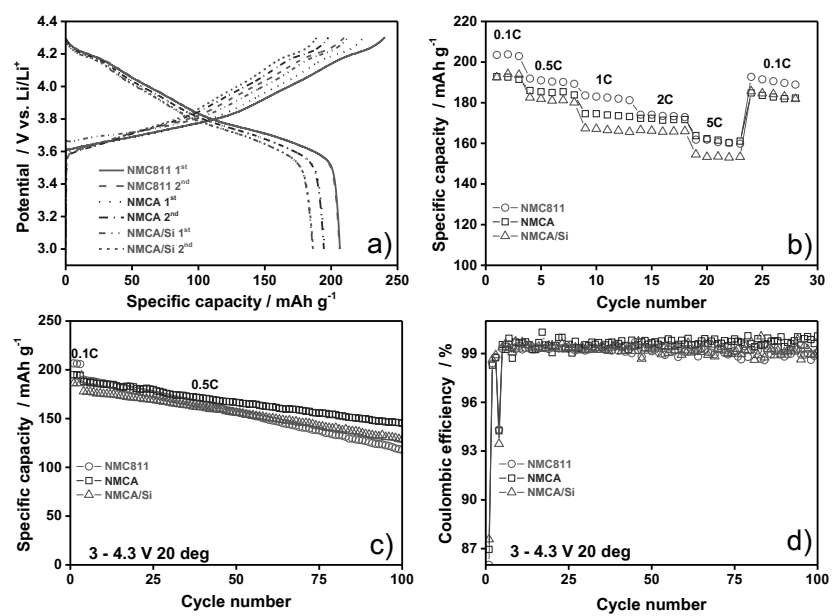

Figure 3. Cycling data with LP 40 and a cut-off of $4.3 \mathrm{~V}$ of NMC811, NMCA and $\mathrm{SiO}_{2}$ surface treated NMCA. a) First and second cycle voltage profile at $\mathrm{C} / 10, \mathrm{~b}$ ) rate capability to test from $\mathrm{C} / 10$ to $5 \mathrm{C}, \mathrm{c}$ ) capacity retention for 100 cycles at $\mathrm{C} / 2$, d) coulombic efficiencies during cycling. 
NMC 811 also outperformed NMCA and $\mathrm{SiO}_{2}$-treated NMCA up to a discharge rate of $2 \mathrm{C}$, for which the capacity of $\mathrm{NMCA}$ was almost equal to the capacity of NMC811. At high discharge rates of 5C, both NMC811 and NMCA reached capacities of over 160 mAhg-1 whilst the $\mathrm{SiO}_{2}$ treated samples showed slightly lower capacities at all rates. This might be caused by an increased resistivity due to $\mathrm{Si}$ on the particle surface. Interestingly, both NMCA and $\mathrm{SiO}_{2}$ treated NMCA showed no loss in capacity when increasing the discharge rate from $1 \mathrm{C}$ to $2 \mathrm{C}$. Clear differences were visible in the long term cyclability in that NMC811 had a capacity retention of only $62 \%$ after 100 cycles, whilst NMCA showed a capacity retention of $78 \%$. The coulombic efficiency was between $99 \%$ and $100 \%$ in all cases, with NMCA showing the highest in average. The $\mathrm{SiO}_{2}$ surface treatment did not improve the cyclability.

It is assumed that the NMC811 sample, consisting of agglomerated secondary particles, undergoes the well-described grain boundary cracking during cycling. This causes more surface to be exposed to the electrolyte and consequently greater CEI formation. To analyze the failure mechanism of the NMCA, a cell was disassembled after 100 cycles and a FIB-cut cross section was analyzed by (S)TEM in combination with EDS and EELS.

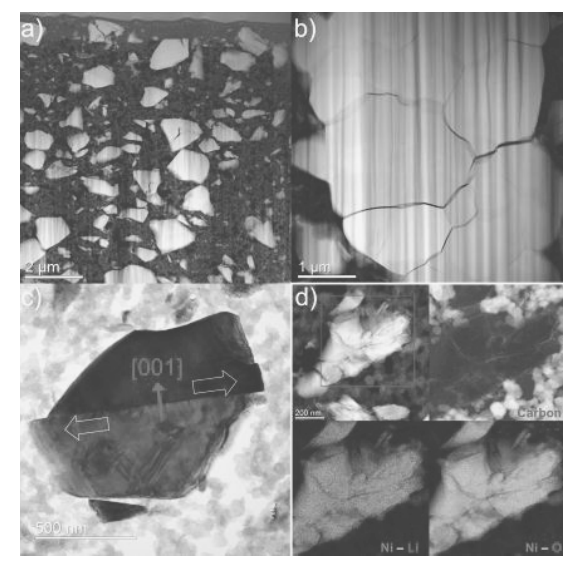

Figure 4. Post-mortem (S)TEM analysis of a NMCA sample after 100 cycles. a-b) HAADF STEM micrographs of the electrode cross section. c) Bright field (BF) TEM images that show how one particle (originally a single crystal) cracks and slides apart on the hexagonal (001) plane. d) HAADF STEM micrograph and element mapping of C, Li and $\mathrm{Ni}$ of a shattered particle.

The NMCA electrode consisted mainly of single crystals (figure 4(a)), however some secondary particles were present (figure 4(b)). The secondary particles consisted of large grains in the range of 1-2 $\mu \mathrm{m}$ and showed the typical grain boundary fracturing as described in literature.[9] However, the NMCA grains were much bigger than the primary particles of NMC811 (figure (2)) and hence less new surface is generated upon grain boundary fracture. The single crystals however showed a different failure mode: Many of them exhibited intraparticle fractures. Those were dominantly present normal to the lattice c-direction (figure 4(c)). This cleavage is believed to be caused due to stresses at high degrees of delithiation. Several studies have shown the $\mathrm{C}$ lattice parameter to contract upon the H2-H3 transition and this is assumed to be responsible for the grain boundary cracking. $[9,10,11]$ We believe that the same mechanism is responsible for cleavage observed in micron sized NMCA single crystals. Figure 4(d) shows a HAADF STEM micrograph of a fractured NMCA particle with a $\mathrm{C}$ element map and EELS element maps comparing $\mathrm{Ni}$ and $\mathrm{Li}$, as well as $\mathrm{Ni}$ and $\mathrm{O}$ distributions. From those maps 
it is clearly seen that both $\mathrm{Li}$ and $\mathrm{O}$ signals extend beyond the $\mathrm{Ni}$ signal. The same is true for the $\mathrm{C}$ distribution map, and here also the $\mathrm{C}$ signal is clearly seen on the inside of the particle cracks. This data suggests interphase formation around the particles and also on new surfaces exposed to the electrolyte by particle fracture. We hence conclude that CEI formation is at least partly responsible for the degradation and explains why the capacity retention NMCA comprising of bigger particles is superior compared to polycrystalline NMC811. The effect of the low Al content on stability cannot be concluded here.

As the electrolyte is at least partly responsible for the capacity degradation, the materials were cycled in an electrolyte in which EC was replaced by FEC. Figure 5 shows the capacity retention for 100 cycles at $\mathrm{C} / 2$ after three conditioning cycles at $\mathrm{C} / 10$. Figure 5(a) shows retention under the same test conditions as in figure 3, whilst figure 5 (b) shows performance in a broader voltage window of $3.0-4.5 \mathrm{~V} \mathrm{vs} \mathrm{Li} / \mathrm{Li}^{+}$and at $45^{\circ} \mathrm{C}$. Figure 5(c) shows a linear sweep voltammogram of both electrolytes from 3.0 to $6.0 \mathrm{~V}$ vs $\mathrm{Li} / \mathrm{Li}^{+}$.
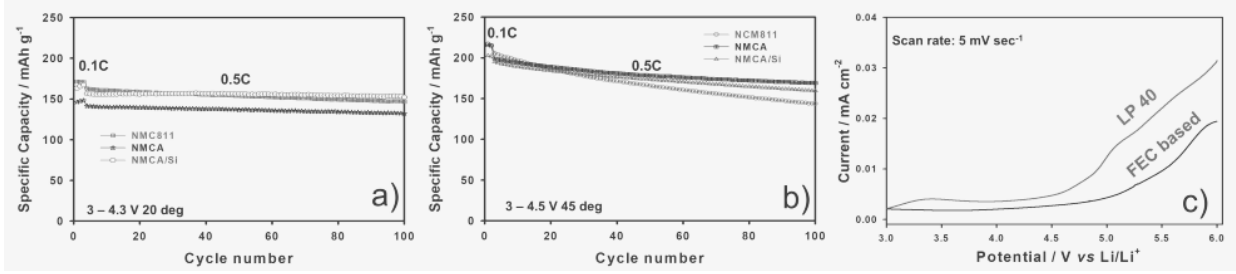

Figure 5. a) Capacity retention for 100 cycles at $\mathrm{C} / 2$ and a cut-off of $4.3 \mathrm{~V}$ at $20^{\circ} \mathrm{C}$ using the $\mathrm{FEC}$ based electrolyte. b) Capacity retention for 100 cycles at $\mathrm{C} / 2$ and a cut-off of $4.5 \mathrm{~V}$ at $45^{\circ} \mathrm{C}$ using the $\mathrm{FEC}$ based electrolyte c) Linear sweep voltammogram of LP 40 and the FEC based electrolyte from 3.0 to $6.0 \mathrm{~V}$ and a sweep rate of $5 \mathrm{mVs}^{-1}$

Under the same cycling conditions as shown in figure 3, all samples showed a reduced capacity in the FEC based electrolyte. The initial discharge capacity of NMC811 was $177 \mathrm{mAhg}^{-1}$, NMCA showed $146 \mathrm{mAhg}^{-1}$ and the $\mathrm{SiO}_{2}$ treated NMCA demonstrated $163 \mathrm{mAhg}^{-1}$. Why NMCA had a more compromised capacity in this setup cannot be concluded yet. We believe that the capacity is in all cases reduced either by poor wetting or a lower ionic conductivity of the electrolyte. Remarkably, the capacity retention after 100 cycles was 90, 94 and $97 \%$ respectively. To alleviate wetting or conductivity issues, and to test the materials under severe conditions, cells were also cycled up to $4.5 \mathrm{~V}$ vs $\mathrm{Li} / \mathrm{Li}^{+}$at $45{ }^{\circ} \mathrm{C}$. Under these conditions, NMC811 reached $217 \mathrm{mAhg}^{-1}$ during the first discharge, NMCA $216 \mathrm{mAhg}^{-1}$ and the $\mathrm{SiO}_{2}$ treated NMCA $203 \mathrm{mAhg}^{-1}$. Even under these conditions, the capacity retention was $71 \%, 85 \%$ and $82 \%$ respectively, clarifying the huge influence of the electrolyte on the cyclability of Ni-rich layered oxides. The liner sweep voltammogram of both electrolytes shows an onset to low current signal for the LP40 electrolyte already at $3.2 \mathrm{~V} \mathrm{vs} \mathrm{Li} / \mathrm{Li}^{+}$. The onset of anodic decomposition in this case is in the range of $4.2-4.3 \mathrm{~V}$ vs $\mathrm{Li} / \mathrm{Li}^{+}$. For the FEC-based electrolyte, the onset is delayed to values of about $4.5 \mathrm{~V}$, which would imply reduced electrolyte decomposition on the cathode and a positive influence on the cyclability.

\section{CONCLUSIONS:}

The Ni-rich layered oxides $\mathrm{LiNi}_{0.8} \mathrm{Mn}_{0.10} \mathrm{Co}_{0.1} \mathrm{O}_{2}$ and $\mathrm{LiNi}_{0.83} \mathrm{Mn}_{0.06} \mathrm{Co}_{0.09} \mathrm{Al}_{0.1} \mathrm{O}_{2}$ were successfully synthesized by an oxalic acid co-precipitation with subsequent annealing. By functionalization of the calcined NMCA precursor with APTES, an 
incomplete surface decoration with $\mathrm{SiO}_{2}$ was achieved. Compositional gradients or the presence of $\mathrm{Al}^{3+}$ resulted in increased crystal growth during annealing. NMCA and $\mathrm{SiO}_{2}$ decorated NMCA showed improved cyclability compared to NMC811 in LP40 electrolyte. However, the incomplete $\mathrm{SiO}_{2}$ coverage imparted no improvement in stability compared to bare NMCA. Post-mortem TEM revealed the NMCA electrodes to mainly consist of single crystals. Furthermore, crystal cleavage preferably normal to the [001] lattice direction was detected. EELS showed a Li, C and O enriched surface layer on the particle surface, and inside particle fractures after cycling. These signals probably correspond to electrolyte degradation products. All samples showed better cycling stability in FEC based electrolyte, but reduced capacities when cycled under the same conditions as in LP40. Even at $45^{\circ} \mathrm{C}$ and a cut-off voltage of $4.5 \mathrm{~V}$ the NMCA samples retained $85 \%$ of its initial capacity after 100 cycles.

\section{ACKNOWLEDGEMENTS:}

The authors gratefully acknowledge the Research Council of Norway for financial support of the HiCath project under the grant number 280910.

\section{REFERENCES:}

[1] R. Schmuch, R. Wagner, G. Hörpel, T. Placke, M. Winter, Nat. Energy 3, 267-278 (2018).

[2] H.J. Noh, S. Youn, C.S. Yoon, Y.K. Sun, J. Power Sources 233, 121-130 (2013).

[3] Y.-K. Sun, S.-T. Myung, B.-C. Park, J. Prakash, I. Belharouak, K. Amine, Nat. Mater. 8, 320-324 (2009).

[4] A. Manthiram, J.C. Knight, S.-T. Myung, S.-M. Oh, Y.-K. Sun, Adv. Energy Mater. 6, 1501010 (2016).

[5] S. Hwang, W. Chang, S.M. Kim, D. Su, D.H. Kim, J.Y. Lee, K.Y. Chung, E.A. Stach, Chem. Mater. 26, 1084-1092 (2014).

[6] F. Lin, I. M. Markus, D. Nordlund, T-C. Weng, M. D. Asta, H. L. Xin, M. M. Doeff, Nat. Comm. 5, 3529 (2014).

[7] J.H. Lee, C.S. Yoon, J.-Y. Hwang, S.-J. Kim, F. Maglia, P. Lamp, S.-T. Myung, Y.-K. Sun, Energy Environ. Sci. 9, 2152-2158 (2016).

[8] A. Manthiram, B. Song, W. Li, Energy Storage Materials 6, 125-139 (2017).

[9] U-H. Kim, LY. Kuo, P. Kaghazchi, C. S. Yoon, and Y-K. Su, ACS Energy Lett. 4, 576-582 (2019).

[10] M. Cormier, N. Zhang, A. Liu, H. Li, J. Inglis, J.R. Dahn, J. Electrochem. Soc. 166, A2826-2833 (2019).

[11] H.H. Ryu, K.J. Park, C.S. Yoon, Y.K. Sun, Chem Mater., 30, 1155-1163 (2018).

[12] H. Li, M. Cormier, N. Zhang, J. Inglis, J. Li, J. R. Dahn, J. Electrochem. Soc. 166, A429A439 (2019)

[13] D. Mohanty, K. Dahlberg, D.M. King, L.A. David, A.S. Sefat, D.L. Wood, C. Daniel, S. Dhar, V. Mahajan, M. Lee, F. Albano, Sci. Rep. 6, 26532 (2016).

[14] W. Zhu, X. Huang, T. Liu, Z. Xie, Y. Wang, K. Tian, L. Bu, H. Wang, L. Gao, J. Zhao, Coatings 9, 92 (2019).

[15] W. Zhao, G. Zheng, M. Lin, W. Zhao, D. Li, X. Guan, Y. Ji, G.F. Ortiz, Y. Yang, J. Power Sources 380, 149-157 (2018).

[16] J. Cha, J.-G. Han, J. Hwang, J. Cho, N.-S. Choi, J. Power Sources 357, 97-106 (2017).

[17] Y.-K. Sun, B.-C. Park, K. Amine, I. Belharouak, S.-T. Myung, J. Prakash, Nat. Mater. 8, 320-324 (2009).

[18] H. Li, J. Li, X. Ma, J.R. Dahn, J. Electrochem. Soc. 165 , A1038-A1045 (2018). 